\title{
EDUCAÇÃO POPULAR E PEDAGOGIA(S) DA PRODUÇÃO ASSOCIADA*
}

\begin{abstract}
RESUMO: Compreendendo os processos produtivos como espaços/tempos da formação humana, tecemos considerações sobre os horizontes econômico-sociais, explícita ou implicitamente presentes nos processos de formação de trabalhadores associados na produção - processos estes promovidos pelos "técnicos" em economia (popular) solidária. Vislumbramos uma pedagogia associada que contribua não apenas para questionar e driblar a perversa lógica excludente do mercado capitalista, mas também para cultivar no interior da sociedade de classes - os germes de uma cultura do trabalho que contrarie a lógica do capital. Tendo como fonte inspiradora dois materiais educativos que servem como referência para os educadores/trabalhadores em economia (popular) solidária, reivindicamos a articulação entre práxis produtiva e práxis educativa, o que requer, dentre outros, o (re)encontro entre trabalho e educação, economia popular e educação popular.
\end{abstract}

Palavras-chave: Trabalho e educação. Economia popular solidária. Educação popular. Formação de trabalhadores associados na produção. Pedagogia da produção associada.

\section{Popular education ANd COllaborative PRODUCTION PEDAGogy(IES)}

ABSTRACT: Understanding the productive processes as spaces/ times of human development, we consider the social and economic perspectives, explicitly or implicitly present in the training processes of workers associated in production - processes that are

* Como algumas modificações/atualizações, este artigo contém partes do capítulo II do livro Economia popular e cultura do trabalho: pedagogia (s) da produção associada (Tiriba, 2001).

** Doutora em Ciência Política e Sociologia pela Universidade Complutense de Madrid e professora da Faculdade de Educação da Universidade Federal Fluminense (UFF). E-mail: liatiriba@oi.com.br 
developed by "technicians" in (popular) collaborative economy. We foresee a collaborative production pedagogy that may contribute not only to question and dodge the cruel and exclusive logic of capitalism, but also to spread - within a class society - the germs of a working culture able to oppose the logic of capitalism. Inspired by two educational materials that are a guiding light to educators/workers in collaborative (popular) economy, we pursue the productive/educational praxis integration, which requires, among other things, that work, education, popular economy and popular education be (re)united.

Key words: Work and education. Popular collaborative economy. Popular education. Training of workers associated in production. Pedagogy of collaborative production.

\section{Trabalho e sobrevivência: a educação na ótica do capital e do trabalho}

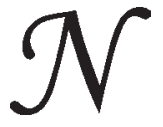

ão apenas, mas principalmente nos países periféricos (onde não vivemos plenamente o Estado do Bem-Estar Social), para os trabalhadores que perderam ou nunca adquiriram o status de pertencer ao "quadro de funcionários da empresa tal", vale qualquer estratégia de trabalho e de sobrevivência ${ }^{1}$ que lhes garanta a reprodução da vida. No atual contexto da crise estrutural do emprego, em que o fordismo dá lugar ao modo de acumulação flexível (acompanhado do modelo neoliberal de regulamentação social) e no qual as pessoas estão famintas por comida, moradia, educação, lutando pela preservação de sua saúde física e mental, carecemos de maior sensibilidade para reconhecer o que Thompson (1979) definiu como economia moral das multidóes. Tendo como referência a Inglaterra do século XVIII, o autor analisa as formas pelas quais os seres humanos, acumulando forças individuais e energias coletivas, materializam sua capacidade para encontrar os meios para produção social de sua existência.

Partimos do pressuposto de que as atividades da economia popular atravessam e estão presentes em todas as formações econômico-sociais. No entanto, com a acumulação flexível e as conseqüentes mudanças na estrutura do mercado de trabalho, que acarretaram o desemprego e o aumento da pobreza, estas atividades tornam-se agora mais visíveis, na medida em que proliferam sobremaneira, ocupando não apenas as calçadas dos centros urbanos, mas também o meio da rua, onde trabalham comedores de 
fogo e crianças malabaristas, entre outros. Também é possível constatar que, mesmo para aqueles que conseguem manter seus postos no mercado (assalariado) de trabalho, é preciso criar, para além da empresa capitalista, outras estratégias de trabalho e de sobrevivência que garantam a reprodução ampliada da vida. ${ }^{2}$ No entanto, entre as diversas iniciativas econômicas populares, é preciso distinguir as atividades da economia popular das atividades ditas empreendedoras, entre as quais se destacam as estratégias de gestão coletiva dos meios de produção - como organização de microempresas, cooperativas e empresas familiares -, as quais vêm sendo úteis à reestruturação produtiva e à nova informalidade, requerida pela flexibilização das relações entre capital e trabalho (Tavares, 2004).

Embora os economistas (neoclássicos ou pós-modernos da burguesia) insistam em apresentar a economia formal e a economia informal ${ }^{3}$ como antinomias, sabemos que as mesmas se constituem como espaços/ tempos diferenciados, mas complementares da economia capitalista. Assim, para analisar a multiplicidade e complexidade das relaçôes econômico-sociais, recorremos ao conceito de economia popular - conceito que nos ajuda a compreender que, no interior do modo de produção capitalista, subsistem outras formas de produzir, distribuir e consumir, cuja racionalidade econômica distingue-se da racionalidade do capital. Como Razeto (1991), pensamos que não há apenas um mercado (o capitalista); no interior do mercado global podemos encontrar outros mercados, nos quais os bens econômicos fluem e transitam entre as pessoas através de relações econômicas de comensalidade, reciprocidade, cooperação e doação. Assim, não pressupondo a exploração do trabalho, a economia popular compreende o conjunto de atividades econômicas e práticas sociais desenvolvidas pelos setores populares, no sentido de garantir a reprodução ampliada da vida.

Transcendendo a obtenção de ganhos monetários ou materiais, além de cooperativas, grupos de produção e mercados populares, também são exemplos de atividades da economia popular o mutirão para limpeza do valão, a ajuda dos amigos para o conserto do telhado, a organização de redes de trocas, entre outros. ${ }^{4}$ Tornando-se mais nítida com a crise estrutural do trabalho assalariado, a economia popular como trabalho produtivo para o Trabalho (e, para o Capital, quando dele se apropria), contém os germes de uma cultura do trabalho de novo tipo - a qual é elemento constituinte de um novo modo de produção da existência humana. E é exatamente no sentido de fortalecer e dar organicidade 
às iniciativas associativas da economia popular que, hoje, se constrói e se fortalece, em nível nacional e internacional, o movimento por uma economia popular solidária. ${ }^{5}$

Considerando que, no Brasil, os trabalhadores urbanos têm em média quatro anos de escolaridade, ou seja, além de terem sido expulsos de um mercado, foram expulsos precocemente da escola, quais são os desafios dos educadores na formação dos trabalhadores associados na produção? Apesar de não nos faltarem denúncias sobre o caráter dual da escola capitalista e o caráter utilitarista dos processos educativos, cujo horizonte é atender aos interesses do mercado (capitalista); apesar da negação da força de trabalho como mercadoria, pouco temos avançado em projetos de formação humana que ultrapassem os muros do mercado de trabalho. Sem nos deixar enganar com o discurso neoliberal que apregoa a educação para o empreendedorismo (ou seja, para a gestão do próprio negócio), um dos desafios é articular trabalho e educação, de maneira a contribuir para que os trabalhadores associados possam mobilizar suas energias em torno de um projeto de desenvolvimento econômico que privilegie a hegemonia do trabalho sobre o capital. Assim, nunca é demais refletir em que medida os projetos educativos, em especial, aqueles promovidos pelos "técnicos" que (de fora) estimulam, apóiam e assessoram as iniciativas dos atores da economia popular (os que pegam pesado no trabalho), contribuem ora para reproduzir a lógica excludente do mercado capitalista, ora para criar e fortalecer novas relações econômicas e de convivência social.

Mercados e outros mercados: o técnico e o político na educação popular e na economia popular

Na perspectiva da emancipação dos trabalhadores associados, ainda são poucos os estudos que, de forma aprofundada, vêm tentando articular trabalho e educação popular. Partindo da premissa marxiana, que considera o trabalho como princípio educativo, pensamos que um de nossos desafios é descobrir como articular estes dois campos de conhecimento e de ação, por meio de um processo práxico que redimensione a racionalidade dos processos educativos em consonância com a racionalidade dos processos de trabalho e das relações econômico-sociais que os trabalhadores pretendem construir. Como é possível redimensioná-las? A discussão sobre a viabilidade econômica dos empreendimentos associativos, por exemplo, pode nos ajudar a refletir sobre este desafio. (Para isso, teremos como fonte 
de referência e inspiração um material didático, produzido por uma organização não-governamental).

Para os trabalhadores que não tiveram acesso a uma educação básica de qualidade social, e que historicamente estiveram relegados às tarefas de execução, a questão da viabilidade econômica de suas organizações é um tema que os preocupa sobremaneira, constituindo-se hoje em dia como um importante conteúdo programático nos cursos de formação. Sem dúvida, um dos problemas dos trabalhadores associados na produção é a sua pouca familiaridade com as práticas de administração e gestão e a incipiente maneira com que têm tratado as questôes econômicas e financeiras. Para alguns educadores, a metodologia consiste em que os trabalhadores formulem perguntas sobre o empreendimento que organizaram ou pretendem organizar e, depois, tentem respondê-las de maneira a "unir eficiência com um processo democrático, participativo e solidário" (Capina, 1998, p. 5). Contudo, se, de acordo com o material didático, "o que interessa é buscar quem nos paga o melhor preço" (idem, ibid., p. 35), talvez já não possamos falar de uma economia dos setores populares a partir de um novo horizonte, mas de uma racionalidade econômica e de uma racionalidade educativa confusas e contraditórias. $\mathrm{Na}$ verdade, o que ocorre é que não só os trabalhadores associados, como também nós (os chamados intelectuais ou técnicos) seguimos com a dificuldade - e, logicamente, o desafio - de relacionar teoria e prática, de articular o técnico ao político, de vislumbrar uma cultura do trabalho que não fique apenas nas nuvens, mas que possa, paulatinamente, materializar-se no chão da produção associada.

É ao longo do processo de trabalho e de outros espaços e tempos de produção de sua existência que o grupo de trabalhadores elabora suas perguntas, busca as respostas, volta a elaborar as perguntas, confrontando cotidianamente as condições objetivas e subjetivas do mundo vivido com o mundo sonhado. Neste sentido, não podemos falar da importância de um estudo, mas da necessidade de aprender a fazer muitos estudos de viabilidade, em que as perguntas e respostas se apresentam permanentemente aos trabalhadores, em um processo em que a práxis produtiva se constitui como princípio educativo. Pensamos que as perguntas que os trabalhadores associados fazem a si mesmos não podem ser concebidas como se fossem questôes cujas respostas se situam no campo técnico (propriamente dito), pois o conteúdo e a forma como se pergunta nunca são neutros (por mais que alguém pretenda), mas pressupõem um de- 
terminado tipo e grau de compromisso do sujeito com o objeto em questão. Ou seja, não se trata simplesmente de decidir sobre "isso ou aquilo", mas de descobrir o que ainda está oculto no cotidiano, buscando soluções técnico-políticas que provisoriamente possam dar respostas ao que é difícil e contraditório. Em outras palavras, o esforço para tornar viável a organização econômica pressupõe um estudo sobre a possibilidade de que, tecnicamente, os trabalhadores possam tornar viável seu projeto político. A procura de uma práxis que contemple a unidade entre os objetivos econômicos e os objetivos sociais é uma das chaves da educação dos trabalhadores associados na produção, a qual é compreendida como processo permanente e como resultado provisório de ação-reflexão-ação.

Se pretendemos combinar eficiência com um "processo democrático, participativo, transparente e solidário", há de se perguntar que democracia queremos, o que entendemos por solidariedade, buscando as diferenças e similaridades das "ações cidadãs" estimuladas pelos diferentes agentes da economia popular. As definições sobre "o quê os trabalhadores vão produzir", por exemplo, vão depender de um estudo de mercado. Não obstante, outras perguntas se fazem necessárias: Quem será beneficiado com o produto? Quais são as necessidades reais da comunidade local? Em que medida é possivel atender às necessidades da comunidade? De que maneira? A definição de "para quem vamos vender" e se "vale a pena produzir", além de ter como referência o que os trabalhadores entendem por necessidades humanas, pressupóe a compreensão dos conceitos de valor de uso e valor de troca, até porque, no capitalismo, o segundo se sobrepõe ao primeiro, provocando a produção de riqueza e a degradação do planeta.

Diferentemente dos processos de auto-ajuda promovidos pelos governos conservadores, empresários e por outros pseudo-aliados dos excluídos do chamado mercado formal de trabalho, o objetivo da educação popular não pode ser o de contribuir para aliviar a pobreza e tampouco de ajustar as "competências básicas" dos trabalhadores para que consigam competir no mercado, desconsiderando as necessidades reais e imediatas das camadas socialmente desfavorecidas. A educação popular, ao contrário da educação bancária (Freire, 1975), tem como um de seus objetivos questionar a atual lógica excludente do mercado e, como conseqüência, criar alternativas para ela. Nesse sentido, vinculado a essas e outras perguntas, estaria também a descoberta, por meio de um processo de ação-reflexão-ação, do que é o mercado global e que, mesmo que o mercado de intercâmbio seja hegemônico em nossa sociedade, existem 
outros mercados que se caracterizam por diferentes relaçóes econômicas: relações de cooperação, de reciprocidade etc. No horizonte de constituição de um mercado solidário que se caracterize por relações econômicas desta natureza, vale questionar: Quem são os consumidores que os trabalhadores vão privilegiar? Os do shopping center ou os da comunidade? É possivel inserir-se tanto na esfera do mercado de intercâmbios como na do mercado solidário? Com que critérios? Além disso, quais são as implicaçôes políticas dos diferentes tipos de relação produtor-consumidor no processo de circulação de mercadorias?

Responder a essas perguntas pressupõe não só um aprendizado técnico, como também a definição e redefinição de um projeto político relativo à possibilidade de, mesmo no interior de uma sociedade de mercado, estabelecer novas relaçóes sociais e econômicas.

É indiscutível que os trabalhadores associados na produção precisam dominar as operações básicas para fazer as contas, avaliar qual é a atual situação econômica e projetar as metas de produção e comercialização que garantam a remuneração de seus integrantes e a manutenção da própria unidade econômica. Além de calcular matematicamente, também necessitam de formação política para definir quais os tipos de investimentos que serão necessários para isso. Os investimentos serão oriundos de instituiçôes beneficentes? Serão considerados como aporte de capital ou como aporte de força de trabalho? Se, para os teóricos da economia popular, parece ser óbvio que a escolha de um determinado tipo de investimento interfere e, por sua vez, condiciona as relações entre os atores econômicos, não necessariamente $a$ priori, está claro para os trabalhadores quais são as condições objetivo-subjetivas que materializam as contradiçóes entre capital e trabalho. Na prática, tampouco está claro como o trabalho pode transformar-se no principal fator de produção, o qual dá sentido e determina os demais fatores de produção (Razeto, 1991).

Ainda sobre os investimentos, para obter uma produção planejada, os trabalhadores precisam escolher as máquinas e equipamentos, o que, por sua vez, pressupóe conhecimentos mínimos sobre os meios de produção, sobre o desenvolvimento tecnológico e os significados da relação entre os seres humanos e os instrumentos de trabalho. Neste processo educativo, tampouco é possível esquecer dos pressupostos da divisão social e técnica do trabalho e da questão da socialização do conhecimento, perguntando-nos os porquês, de uma maneira geral, da produção do saber ser concebida como algo que acontece depois do processo de traba- 
Educação popular e pedagogia(s) da produção associada

lho: nas reuniōes, assembléias, nos cursos de capacitação... $\mathrm{Na}$ verdade, os dispositivos tecnológicos, a forma como se organiza a produção e se distribui o trabalho é o que vai permitir ou não a socialização do saber in loco.

Outro aspecto a se considerar num processo educativo que redimensione a racionalidade econômica é como pensar numa gestão cooperativa de maneira a garantir - horizontalmente - o exercício de falar, escutar, duvidar, criticar, sugerir e decidir? Como a forma de participação pode favorecer que todos, e não só alguns, se tornem senhores do processo de produção? Para que o coletivo de trabalhadores possa, efetivamente, dirigir e controlar aqueles que transitoriamente o representam, quais seriam os conteúdos técnicos e políticos de uma "educação socialmente produtiva" (Gutiérrez, 1993) e permanente, que se desenvolva no interior das organizações econômicas populares? No cotidiano da produção, é possível ir mais além do trabalho polivalente, promovendo um processo em que todos - e não somente alguns - sejam capazes de compreender os princípios fundamentais da gestão, tendo acesso aos conhecimentos necessários que os permitam também questionar, opinar, propor mudanças... enfim, decidir sobre qual o tipo de gestão administrativa, financeira, jurídica que melhor coincide com os interesses coletivos?

\section{Educação popular e pedagogia da produção associada}

Para refletir sobre os fundamentos de uma pedagogia da produção associada, consideramos pelo menos três premissas teórico-práticas. A primeira é que, na busca incessante para ganhar o pão de cada dia, o trabalho torna-se não apenas um princípio educativo, mas também um fim educativo. Os trabalhadores têm aprendido na "escola da vida" que não tem sido suficiente reivindicar do Estado seus direitos mínimos de cidadania. $\mathrm{O}$ abandono do Estado em relação às necessidades básicas de alimentação, moradia, educação etc. tem influenciado na construção de uma cidadania ativa - que vai mais além do protesto e da reivindicação. A segunda premissa é que, mediante a práxis, os seres humanos constroem a realidade humano-social. Inclusive não tendo acesso à escolarização básica, a estrutura da divisão do trabalho - incluindo, aí, os processos de discussão, participação e decisão - é o que vem permitindo ampliar, em maior ou menor grau, os saberes sobre o mundo do trabalho e a vida 
em sociedade. Assim como para a pedagogia da fábrica (Kuenzer, 1986), na medida em que os integrantes destas unidades econômicas aprendem os conhecimentos específicos para produzir os bens materiais para sua sobrevivência, aprendem também os valores, os comportamentos que são necessários para o estabelecimento de determinadas relações de produção. $\mathrm{O}$ terceiro pressuposto é que, como nos indica Razeto (1993), nenhuma economia se torna solidária porque as pessoas tornam-se boas ou generosas, mas quando o trabalho e a comunidade tornam-se os fatores que determinam os demais fatores da produção. A solidariedade somente pode se tornar um valor real na medida em que ela se incorpore na própria organização do trabalho. Assim, o objetivo da educação popular não é que os trabalhadores associados apenas assimilem, de forma abstrata, os pressupostos filosóficos e políticos de uma nova cultura do trabalho ou de uma economia que se pretenda solidária. Não basta idealizar uma nova cultura do trabalho ou uma cultura popular baseada no trabalho participativo e solidário. Mais do que nunca, é preciso aprender a construí-la, materializála no dia-a-dia da produção.

Entendemos que os processos pedagógicos também se constituem como um elemento da cultura do trabalho, mediando as condiçóes objetivas e subjetivas do processo produtivo. Tratando-se de uma empresa capitalista ou de uma organização econômica popular, a dinâmica da produção é fonte de saberes, adquiridos e produzidos no processo de trabalho. Mas a dura e crua realidade é que os trabalhadores não usufruem de tecnologias de produção que permitam aumentar seu tempo livre e, tampouco, dos fundamentos teórico-metodológicos que lhes permitam articular teoria e prática, de modo a encontrar uma forma mais racional, e ao mesmo tempo mais humanizada, para colocar os meios de produção a seu serviço. Mesmo quando os trabalhadores são os proprietários dos meios de produção, é exatamente o monopólio destes dois instrumentos um dos elementos através dos quais os "homens de negócio" (da classe dominante) asseguram sua condição de dominação. Sem dúvida, os processos produtivos e, especialmente, as experiências de produção associada constituem-se como uma "escola" de formação de trabalhadores. No entanto, a natureza das atividades ali desenvolvidas não permite a reprodução ampliada do saber. Conforme Gramsci (apud Nosella, 1992), quando a escola funciona com seriedade, não deixa tempo para o setor de produção e, o contrário, quem trabalha seriamente somente pode instruir-se através de um enorme esforço. 
Se a relação trabalho-educação tem como pressuposto que o conhecimento produzido na escola tem como fonte inspiradora o saber produzido nas relações sociais, que os homens estabelecem em seu processo de trabalho, a possibilidade de uma ação se transformar em açãotransformadora pode ganhar corpo quando os trabalhadores têm assegurado, pelo menos, o direito à educação básica (fundamental e média). Sendo assim, como parte integrante de um projeto maior que contribua para tornar orgânica a economia popular, consideramos importantes projetos educativos que, articulados com a escola e recuperando os pressupostos da educação popular, sejam capazes de contemplar os trabalhadores que não tiveram acesso ou não conseguiram permanecer na escola e que, frente à crise do emprego, vêm tentando criar suas próprias organizaçôes econômicas. ${ }^{6}$

Referimo-nos a uma perspectiva de educação de trabalhadores que vai mais além de adequar os jovens e adultos às necessidades do mercado (capitalista) - mercado este excludente. E que, sem deixar de considerar as relações econômicas de intercâmbio (características da sociedade capitalista), abra caminhos para descortinar outros mercados, outras relações sociais, cuja racionalidade não está baseada na reprodução ampliada do capital, mas da própria vida. Consideramos que, frente ao problema do desemprego e do aumento da pobreza, os programas de formação profissional não devem deixar de considerar a "vocação econômica" da região, questionando, não obstante, em que medida esta "vocação" (que em última instância está determinada pela lógica do mercado capitalista) tem ocultado e, ao mesmo tempo, sufocado outras vocações, em especial aquelas dos setores populares. Em outras palavras, isso implicaria um processo educativo: a) que, intimamente articulado, com a rede pública de educação, contribua para a formação integral dos trabalhadores; b) que, articulado com o sistema público de geração de trabalho, tenha os movimentos populares como eixo norteador de sua ação; c) que contribua para a criação de redes de produção, comercialização e de socialização e sistematização dos conhecimentos produzidos por aqueles que tentam sobreviver à perversidade da atual lógica do mercado e d) que fortaleça, no interior do mercado global, o mercado específico da economia popular, associativa e autogestionária, de maneira que a mesma possa dialogar e mesmo vir a se confrontar com a economia capitalista.

Vislumbramos propostas de ação que, ao articular trabalho e educação, possam seguir os mesmos caminhos pelos quais muitos trabalha- 
dores vêm tentando organizar seus empreendimentos associativos: articular-se com a comunidade local e com os movimentos populares. Para isso, é preciso descortinar a singularidade e particularidade da unidade econômica, assim como a totalidade de seu bairro, de seu território mais amplo de trabalho: a sociedade em geral. Em outras palavras, vislumbramos um processo educativo que tem como ponto de partida a ação-reflexão-ação e a sistematização do cotidiano do trabalho e da vida, tendo como ponto de chegada a busca de novos valores e práticas que permitam transformar permanentemente as relações de convivência na comunidade onde a organização econômica se localiza.

Para os educadores que, ao mesmo tempo, assumem a postura de pesquisadores, o desafio é ir mais além da pedagogia da fábrica, popularizando o saber acadêmico, sistematizando o saber popular e construindo com os trabalhadores uma pedagogia da produção associada que contribua para a constituição de uma sociedade dos produtores livres associados (no sentido marxiano). Obviamente, não se trata de "ensinar os pescadores a pescar", substituindo o saber popular por um saber "superior" e, tampouco, de transferir para a escola sua responsabilidade em relação às organizações econômicas populares. Ao contrário, trata-se de repensar a escola e de ampliar os espaços educativos que promovam novos saberes e novas práticas sociais. Para isso, um dos pontos de partida da pedagogia da produção associada é compreender as iniciativas populares como instâncias educativas, aprendendo com os trabalhadores as formas como vêm tentando administrar seus empreendimentos.

Se a educação de jovens e adultos trabalhadores deve ser essencialmente presencial (Cabello, 1997), na prática, isso pressupõe que os trabalhadores possam freqüentar uma escola para sistematizar seus conhecimentos e ali buscar novos saberes que contribuam para dar sentido ao seu trabalho e à vida em sociedade. No entanto, pensamos que, por mais que o processo educativo - ao contrário da concepção bancária - favoreça o encontro e o confronto entre os diferentes saberes, tampouco é suficiente a escola como espaço de aprendizagem. Pensando na possibilidade de que a economia popular torne-se não apenas um conteúdo programático ou um tema transversal, mas um dos eixos principais da educação popular, enfatizamos que a articulação trabalho-educação não se esgota nos espaços formais de produção e socialização de conhecimentos. Além disso, seria uma ingenuidade imaginar que os professores e técnicos têm uma larga experiência sobre os dilemas e desafios da economia 
Educação popular e pedagogia(s) da produção associada

popular e que, portanto, estariam aptos para assessorar os trabalhadores sobre os rumos técnicos e políticos de seus projetos de vida e de trabalho. Pensamos que o processo in loco da formação de novas relações sociais e econômicas é instância educativa não só para os trabalhadores associados, mas também para os educadores - o que nos leva a reafirmar que a articulação entre trabalho-educação se estende, necessariamente, aos processos educativos que se configuram no cotidiano da produção associada.

Interessante tem sido a presença de alguns educadores no movimento por uma economia (popular) solidária. Evidentemente, a teoria se produz em consonância com a prática social; uma nova prática produz novos conhecimentos, novos valores, em um processo permanente em que o "próprio educador precisa ser educado" (Marx \& Engels, 1987, p. 12). Tendo em conta os diferentes projetos societários que estão em jogo e inspiram os projetos de formação de trabalhadores associados na produção, outro desafio é como articular as diferentes redes de produção de conhecimentos e de novas práticas sociais: escola, universidade, organização não-governamental, associação de moradores, organizações econômicas populares... Como construir organicamente esta relação?

\section{Recebido em outubro de 2006 e aprovado em março de 2007.}

\section{Notas}

1. Diferentemente de Certeau (2001, p. 47), não utilizamos o termo estratégia como maneiras de fazer o cotidiano que "escondem sob cálculo objetivo a sua relação com o poder que o sustenta, guardado pelo próprio lugar ou pela instituição". A partir do pressuposto de que o poder é algo que, de alguma maneira, está internalizado no cotidiano dos setores populares, não distinguimos tática e estratégia. Como estratégias de sobrevivência, as práticas sociais de mobilização de energias e recursos (lícitos ou ilícitos) que objetivam ganhos materiais ou imateriais, não monetários, necessários para complementar os frutos do trabalho (propriamente ditos), até então insuficientes para garantir a reprodução ampliada da vida.

2. Esta questão está sendo tratada na pesquisa Economia popular, educação e reprodução ampliada da vida: de que vivem os trabalhadores metalúrgicos?, por mim coordenada, no período 2003-2005, com apoio da FAPERJ e CNPq/IC.

3. De acordo com estudo da Universidade Federal do Rio de Janeiro (UFRJ), no Brasil, 58\% dos ocupados estão na atividade informal (ver Informalidade atinge 38,1 milhões no país, Folha de S. Paulo, 8 fev. 2004).

4. Sobre o conceito de economia popular e sua diferenciação do conceito de economia informal, ver Icaza e Tiriba (2003) e Tiriba (2003). 
5. Com a crise do final de 2001, na Argentina, merece nossa atenção o Movimento dos Trabalhadores Desocupados (MTD), bem como as demais experiências dos trabalhadores que passaram a ocupar e recuperar as fábricas que faliram ou foram abandonadas pelos empresários. Para isso, ver Carpintero e Hernández (2002). No caso brasileiro, foi criada, em junho de 2003, no Governo Lula, a Secretaria Nacional da Economia Solidária (MTb); sobre as diversas experiências associativas e autogestionárias no Brasil, ver Singer (2000).

6. Ver, em Tiriba e Picanço (2004), coletânea de artigos sobre concepçôes e práticas de educação de trabalhadores associados.

\section{Referências bibliográficas}

CABELLO, J. La acción educativa como proyecto cultural y social. In: CABEllo, J. (Coord.). Didáctica y educación de personas adulta. Málaga: Algibe, 1997. p. 17-33.

CARPINTERO, E.; HERNÁNDEZ, M. (Coord.). Produciendo realidad: las empresas comunitárias. Buenos Aires: Topía, 2002.

CERTAU, M. A invenção do cotidiano: artes de fazer. Petrópolis: Vozes, 2001.

COOPERAÇÃO E APOIO A PROJETOS DE INSPIRAÇÃO ALTERNATIVA (CAPINA). Puxando o fio da meada: viabilidade econômica de empreendimentos associativos. Rio de Janeiro: Capina, 1998.

FREIRE, P. Pedagogia do oprimido. Rio de Janeiro: Paz \& Terra, 1975.

GUTIÉRREZ, F. Educação comunitária e desenvolvimento sócio-político. In: GadotTi, M.; GutiérRez, F. (Org.). Educação comunitária e economia popular. São Paulo: Cortez, 1993. p. 23-33.

ICAZA, A.; TIRIBA, L. Economia popular. In: CATANI, A. (Org.). A outra economia. Porto Alegre: Veraz, 2003. p. 101-109.

KUENZER, A. Pedagogia da fábrica. São Paulo: Cortez, 1986.

MARX, K.; ENGELS, F. A ideologia alemã (Feuerbach). São Paulo: Hucitec, 1987.

NOSELlA, P. A escola de Gramsci. Porto Alegre: Artes Médicas, 1992.

RAZETO, L. Empresas de trabajadores y economía de mercado. Santiago de Chile: Programa de Economía del Trabajo (PET), 1991. 
RAZETO, L. Los caminos de la economía de solidaridad. Santiago de Chile: Vivarium, 1993.

SINGER, P.; SOUZA, A.R. A economia solidária no Brasil. São Paulo: Contexto, 2000.

TAVARES, M.A. Os fios (in)visiveis da produção. São Paulo; Cortez, 2004. THOMPSON, E.P. A economia moral da multidão inglesa no século XVIII. In: ThOmpson, E.P. Costumes em comum: estudos sobre a cultura popular tradicional. São Paulo: Cia das Letras, 1998.

TIRIBA, L. Economia popular e cultura do trabalho: pedagogia(s) da produção associada. Ijuí: UNIJuí, 2001.

TIRIBA, L. O trabalho no olho da rua: fronteiras da economia popular e da economia informal. Proposta, Rio de Janeiro, v. 30, n. 97, p. 38-49, jun./ago. 2003.

TIRIBA, L.; PICANCO, I. (Org.). Trabalho e educação: arquitetos, abelhas e outros tecelóes da economia popular solidária. Aparecida: Idéias \& Letras, 2004. 